\title{
An integrated approach to in-situ remediation of a former paint manufacturing facility
}

\author{
F. C. Ballesteros, L. F. DeSales \& G. D. Pamintuan \\ Environmental Engineering Graduate Program, \\ University of the Philippines Diliman, Philippines
}

\begin{abstract}
In the Philippines, there are neither regulations nor standards governing the remediation of contaminated sites. Using the United States Environmental Protection Agency (USEPA) Environmental Site Assessment (ESA) Procedure, ESA Phases 1 and 2 were conducted on a contaminated facility suspected of VOCs and TPH. Initial testing using auger drilling up to two (2) meters depth showed at least five (5) impacted areas. The 2.4-hectare property was then subjected to a $5 \mathrm{~m} \times 5 \mathrm{~m}$ drilling grid in the 5 areas and test pitting. The following were found to have contributed to the contamination in the area: an underground storage tank which contained, among other compounds, acetone and esters; a drainage system emptying into a series of settling ponds; and another drainage system which was older but apparently was not part of the plant facility. Most of the subsurface contamination was in the clay layers which were of two kinds: a lighter brown type which was deposited from the nearby mountains, and a dark, organic matter-bearing clay, which has been deposited by an ancient river in the area. Contamination in the clays took the form of a plume which spread out from the storage tank and leakage of TPH from the drainage systems overprinted the plume. A layer of coarser sediments (sand- up to gravel-sized) at depths of 4 meters or more marked the deepest parts of the pit; behaviour of contaminant movement was not easy to follow in this stratum due to the high porosity/permeability. Tests included visual, olfactory, $\mathrm{pH}$, PID and laboratory tests for VOCs and TPH; a correlation between the last two tests was done to lower cost of laboratory testing; water produced during the excavation was chemically treated using $\mathrm{FeCl}_{3}$ before discharging to a nearby creek. Bioremediation using white rot fungus, Phanerochaete chyrsosporium, was done
\end{abstract}


in-situ on VOC-contaminated clays, while TPH-contaminated materials were shipped out for ex-situ treatment.

Keywords: composting, bioremediation, SVOC, developing country.

\section{Background}

A piece of real estate property formerly occupied by a paint manufacturing facility was scheduled for sale to be developed for residential use. The facility is situated on a very gently sloping topography at elevations between 14 to 16 meters above mean sea level. The property is bounded on the southeast by a high wall that separates it from the adjacent property; on the southwest by a road that runs from the southern corner to the western corner; on the northwest by another road; and on the north and northeast by a river. The identified sources of contamination included underground storage tanks (USTs) and product lines. In addition, historical records of the operation of the former paint facility indicated occurrence of several spill and leakage incidents. Aggravating the problem was the decommissioning of site facilities and utilities undertaken by a demolition company contracted by the owner of the facility. Improper disposal of industrial waste may have further increased contamination.

As mandated by law, a thorough environmental site assessment (ESA) should be conducted prior to transfer of ownership of the property. Findings from a previous study indicated possible contamination with hazardous materials including slightly volatile organic compounds (SVOCs). Following these findings, a more comprehensive assessment and subsequent remediation was necessary. Soil and groundwater samples collected from the property showed the presence of the trimethylbenzene, xylene, toluene, and ethylbenzene. Lead was present in the surface water that seeped through the soil.

This paper outlines a remediation strategy for the contamination situation at hand. In a situation where funding constraints characteristic of developing countries, several measures using simple technology requiring minimal expertise are outlined.

\section{Remediation strategy}

The contaminated portion encompassed an area of about $900 \mathrm{~m}^{2}$ with varying depths ranged from 0.5 meter below ground level (mbgl) to $4.8 \mathrm{mbgl}$ where contaminated soil was encountered (Figure 1). To bring down contaminant concentrations to acceptable levels, the remediation task entailed the following approaches namely: a) preventing further contamination by containment of impacted overlying soil b) excavation of impacted soils and c) landfarming treatment d) validation of treatment results. Extent of remediation treatment was based on meeting the acceptance criteria for soil as stipulated in the USEPA Preliminary Remediation Goals for residential and industrial use. 


\subsection{Excavation and trenching}

Using ESA procedures outlined by the USEPA, excavation commenced at areas most likely to be contaminated, i.e., Advance Resins Building Area (Refer to Figure 1). For easier containment, trenching of the whole area was also undertaken. Using a back hoe, small excavations were dug from 1 to $1.5 \mathrm{mbgl}$ deep made all over the property. Excavation of larger pits was also done in areas that are suspected of contamination. This procedure afforded a straightforward way of delineating the extent of contamination.

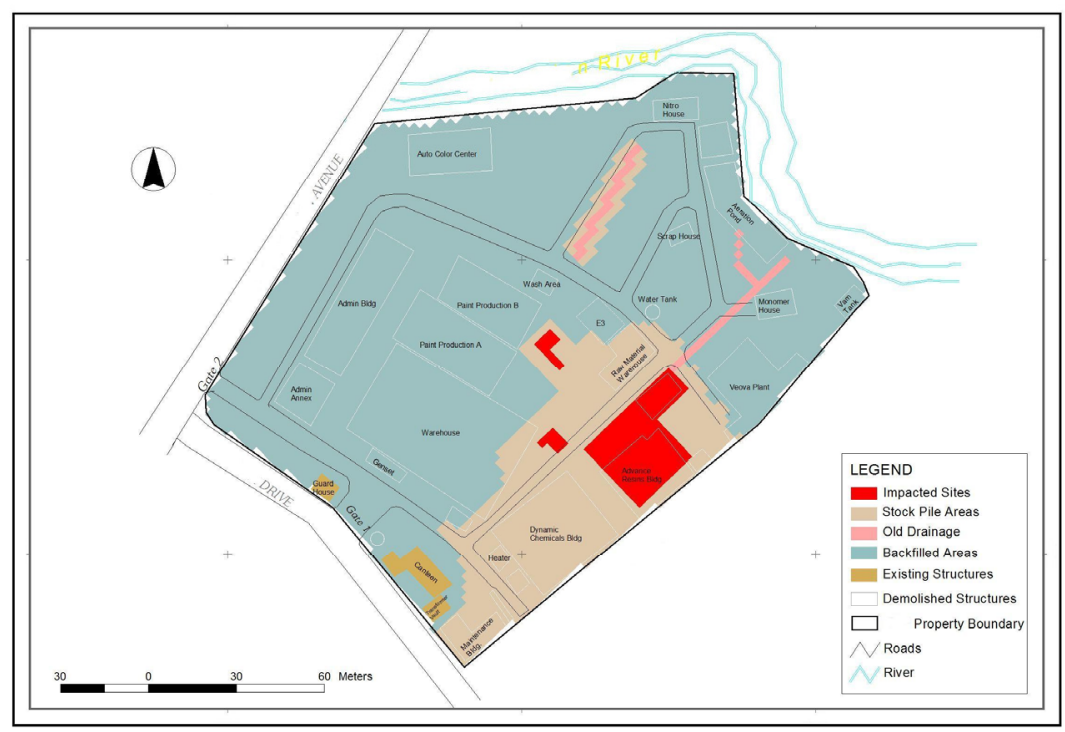

Figure 1: Plant layout showing contaminated areas.

A 30 by 8 meter grid was set up as the treatment area that was previously occupied by the Dynamics building (Figure 1). The thorough procedure for excavation is outlined as follows. For every meter in the grid, a boring core was driven into the soil to create a one (1) meter deep vertical hole. The hole was then covered for 5 minutes in order to collect the released gas into the cavity. A ToxiRAE PID (Photo-Ionization Detector) reading was then taken to determine if the soil is contaminated. The PID is a screening tool that provides rapid VOC measurements in the field. Once the extent of the contaminated area is determined, the impacted soil is excavated. In some cases, the large volume of the impacted soil necessitated that sizeable portions be stockpiled in other parts of the site instead of hauling it to the treatment area. These are mostly those that are too far from the treatment area making hauling impractical.

The excavated soil materials exhibited weak to strong hydrocarbon odor. PID readings obtained from 1,050 sampling points ranged from $0.0 \mathrm{ppm}$ to the 
maximum of 2,000ppm. Trenching of the whole property revealed that contamination was mostly concentrated in the middle of the site. Significant soil contamination was observed in the Advance Resins Building and the Paint Production Area. Impacted soil that showed relatively low PID readings but have moderate to high degree of visual-olfactory signs of contamination were collected together with the excavated materials that showed observable contamination.

\subsection{Landfarming}

About $280 \mathrm{~m}^{3}$ of excavated impacted soil underwent landfarming process (composting) to bring down the level of VOC in the soil material to an acceptable level. Previous studies have demonstrated the viability of composting in the treatment of soils contaminated with organic pollutants (Semple et al. [4]). The treatment process entails mixing with bulking agents and organic amendments such as wood chips, hay, manure, and vegetative (e.g., potato) wastes to ensure adequate porosity and provides a balance of carbon and nitrogen to promote thermophilic, microbial activity. Rice hull provided the bulk of the C: $\mathrm{N}$ requirements while white rot fungus was added as degradation activator. The role of white rot fungus in decontamination of sites from halogenated and alkylated hydrocarbons including PAH, PCB, TNT, and BTEX is well documented (Paszczynski and Crawford [3]; Adinarayana [1]; Canet et al. [2]; Sette et al. [5]). Composting was maintained by regular (weekly) turning of the impacted soil to ensure unexposed soil materials are aerated to allow VOCs to vaporize and enhance microbial degradation. The standard for PID was used to evaluate the level of VOC in the impacted soil. Once the PID readings of treated soil reached $50 \mathrm{ppm}$ (screening level set for the in-situ remediation) or lower, it was backfilled into the pits. Correlation of individual VOC concentration readings with PID readings showed that a threshold of $50 \mathrm{ppm}$ can be safely used to assume that levels of the individual VOCs are below the levels considered acceptable in the ESA $1 / 2$ guidelines.

To ensure no surface recontamination should there be rain episode during treatment, all drainage lines were decommissioned and concrete culverts together with the contents that remained were hauled for offsite treatment.

\subsection{Water treatment}

Water from the excavated contaminated pits was pumped out and treated onsite with the addition of ferric chloride $\left(\mathrm{FeCl}_{3}\right)$ to the contaminated water. The precipitate was treated together with contaminated soil using the landfarming process. The $\mathrm{pH}$ and Chemical Oxygen Demand (COD) of the treated water in each of the drums were recorded and the water passing Philippine regulatory standards was subsequently discharged to a nearby creek. 


\section{Results}

In the absence of applicable Philippine remediation guideline values for the contaminants of concern, the relevant United States Environmental Protection Agency Region 9 Primary Remediation Goals (USEPA PRG9) for residential soil were adopted as the site screening and clean-up criteria.

To save on laboratory costs, a correlation study was made between PID readings and various concentrations of the contaminants listed in Table 1. A calibration curve was constructed which showed that a threshold value of $50 \mathrm{ppm}$ TPH reading of the PID handheld equipment. Consequently, we used this value as the maximum TPH reading to meet the soil acceptance criteria as given in Table 1.

Table 1: $\quad$ Adopted soil screening and clean-up criteria.

\begin{tabular}{|cc|}
\hline Contaminant of Concern & $\begin{array}{c}\text { Soil Screening/Clean-Up Values } \\
(\mathbf{m g} / \mathbf{k g})\end{array}$ \\
\hline Chloroform & 0.3 \\
Trichlorobenzene, $1,2,4-$ & 87 \\
Trimethylbenzene, $1,2,4-$ & 67 \\
Trimethylbenzene, $1,3,5-$ & 47 \\
\hline Isopropylbenzene & 2,200 \\
\hline Propylbenzene, $\mathrm{n}-$ & 240 \\
\hline Butylbenzene, sec- & 220 \\
\hline Naphthalene & 3.9 \\
\hline Xylene, p- & 4,700 \\
Xylene, m- & 4,500 \\
Xylene, o- & 5,300 \\
Toluene & 5,000 \\
\hline Ethylbenzene & 5.7 \\
\hline
\end{tabular}

The total TPH readings of the contaminated soil in the main treatment area showed high values with the highest value recorded at almost $600 \mathrm{ppm}$ (Figure 2). It can be inferred that the individual contaminants used in the correlation study is above the limit as well. Based on ESA 1/2 criteria, the site needs remediation. Treatment using the composting with white rot fungus showed that the concentration levels stabilized at acceptable levels (50 ppm) after 57 days.

In the case of the stockpiled soil treated elsewhere in the property, the process stabilized after the $16^{\text {th }}$ week onwards (Figure 3). 


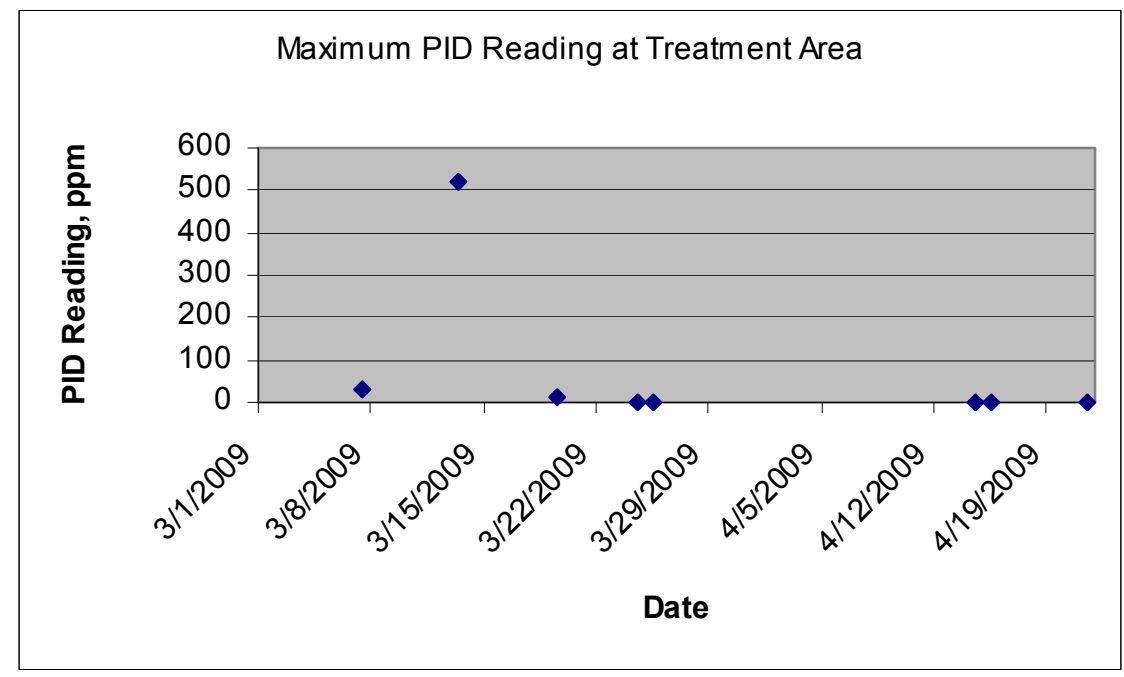

Figure 2: $\quad$ Stockpile monitoring at the treatment area and corresponding PID readings.

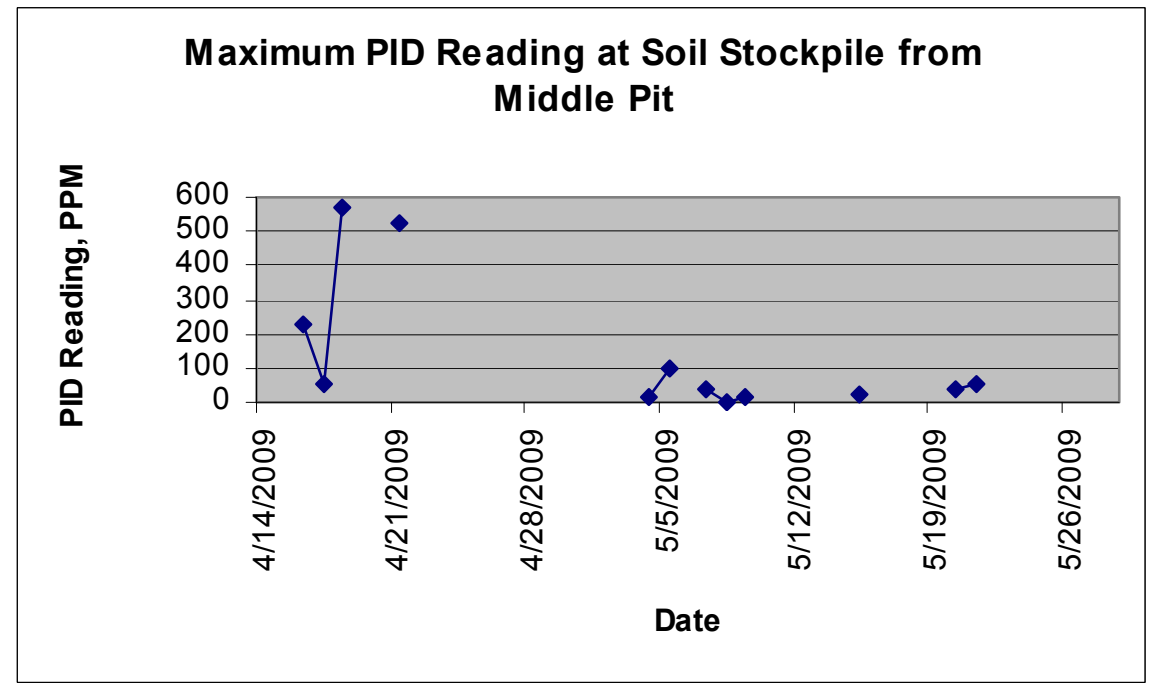

Figure 3: Stock pile monitoring of middle pit soil and corresponding PID readings.

\section{Conclusion}

This exercise was able to demonstrate the feasibility of a simple remediation technique that can be considered appropriate from a developing country 
perspective. It featured the use of Indigenous materials and a cost effective approach to contaminant level determination. Where remediation of contaminated sites can require tremendous capital outlay, the use of white rut fungus composting that requires simple expertise is an excellent alternative and could very well be duplicated in other similar situations.

\section{References}

[1] Adinarayana, R. C. (1995), The potential for white-rot fungi in the treatment of pollutants, Current Opinion in Biotechnology, 6 (3), 320-328.

[2] Canet, R., Birnstingl, J.G., Malcolm, D.G., Lopez-Real, J.M., and Beck, A.J. (2001), Biodegradation of polycyclic aromatic hydrocarbons (PAHs) by native microflora and combinations of white-rot fungi in a coal-tar contaminated soil, Bioresource Technology, 76, (2), 113-117.

[3] Paszczynski, A., \& Crawford, R.L. (1995), Potential for bioremediation of xenobiotic compounds by the white-rot fungus Phanerochaete chrysosporium, Biotechnology Progress, 1995.

[4] Semple, K.T., Reid, B.J., and Fermor, T.R. (2001), Impact of composting strategies on the treatment of soils contaminated with organic pollutants, Environmental Pollution, 112, (2), 269-283.

[5] Sette, L., de Oliveira V.M., and Rodrigues, M.F. (2008), Microbial lignocellulolytic enzymes: industrial applications and future perspectives, Microbiology Australia, 29 (1), 18-20. 